\title{
Las obras pías del VI conde de Fernán Núñez: Un ejemplo de distinción social a través de la caritas ilustrada a finales del siglo XVIII
}

\author{
The Charity of sixth Count of Fernán Núñez: \\ a case of social distinction in the Enlightenment.
}

\author{
José Antonio VIGARA ZAFRA \\ Universidad Nacional de Educación a Distancia
}

RESUMEN: Este trabajo pretende un análisis de las prácticas piadosas desarrolladas por el VI conde de Fernán Núñez en su villa solariega de la provincia de Córdoba durante el último cuarto del siglo XVIII. Para ello se estudian las etapas constructivas y las funciones simbólicas originadas en torno a estas obras. Con ello se esperan extraer consecuencias relativas al análisis de las nuevas estrategias de distinción social generadas por las élites nobiliarias durante la Ilustración.

Palabras clave: Nobleza, Arquitectura del siglo XVIII, Obras pías, VI Conde de Fernán Núñez.

ABSTRACT: This paper tries to analyze the change in charity practices carried out by the sixth Count of Fernán Núñez in his villa. To do this, the phases of completion, the symbolic functions and the social disputes resulting from the construction of this charitable works are described and examined. We claim that this analysis has relevant consequences for the study of the new policies of social distinction of the nobility during the Enlightenment.

Keys words: Nobility, Architecture in the Eighteenth Century, Charity, sixth Count of Fernán Núñez.

Durante la segunda mitad del siglo XVIII el crecimiento de la población urbana en Europa agudizó los problemas sociales en las ciudades, provocando que los gobiernos ilustrados llevaran a cabo una política reformista con el objetivo de atajar los problemas relacionados con la beneficencia, la sanidad y la educación de las clases sociales más des- favorecidas ${ }^{1}$. Como es sabido, los dirigentes ilustrados insistieron fundamentalmente en el intervencionismo estatal para acabar con

${ }^{1}$ Este estudio se ha realizado en el marco del proyecto Políticas en tránsito para la legitimación nobiliaria: narrativas de memoria y estética en la gestión del patrimonio artístico de la nobleza española, HAR2012-36751 del Ministerio de Economía y Competitivad. 
la pobreza y la incultura, concediendo una importancia mayúscula a la construcción de centros comunitarios de índole asistencial y docente, que permitieran sanar y reeducar a buena parte de la población marginada, transformándola en útil para el Estado. Sin embargo, la gran mayoría de estas medidas de carácter filantrópico fracasaron en la práctica a causa de la falta de medios económicos.

En España, estas políticas reformistas comenzaron a aplicarse a finales del reinado de Carlos III y tuvieron su continuación más efectiva con Carlos IV, difuminándose paulatinamente la antigua idea de que las instituciones religiosas eran la única respuesta posible para solucionar este problema en favor de un mayor intervencionismo esta$\mathrm{tal}^{2}$. No obstante, como ocurriera durante la Edad Moderna, el mecenazgo de las obras pías continuó constituyendo una práctica habitual entre las élites nobiliarias, entendido como una de las obligaciones innatas del grupo que les permitió habilitar nuevos escenarios para la distinción social.

Con el presente estudio pretendemos analizar el proyecto global de obras pías diseñado por Carlos José Gutiérrez de los Ríos y Rohan-Chabot, VI conde de Fernán Núñez

\footnotetext{
${ }^{2}$ Entre los autores que afianzaron el nuevo sistema benéfico del siglo XVIII en España, destacaron Ward, Campomanes, Jovellanos, Cabarrús y Foronda, véase: B. WARD, Obra Pía y eficaz modo para remediar la misma gente pobre de España, Valencia, 1750; P. RODRIGUEZ DE CAMPOMANES, Discurso sobre el fomento de la industria popular; Madrid, 1774; M. G. JOVELLANOS, “Discurso acerca de la situación y división de los hospicios con respecto a su salubridad", Obras publicadas e inéditas de Don Gaspar Melchor de Jovellanos, Madrid, 1859, tomo II, pp. 431-435; F. CABARRÚS, "Memoria sobre los Montes Píos, leída en la Real Sociedad Económica de Madrid en 13 de marzo de 1784", en J. SEMPERE GUARINOS, Ensayo de una Biblioteca Española de los mejores escritores del reinado de Carlos III, Madrid, 1785, tomo II, pp. 8-14; V. FORONDA, "Paralelo de la Sociedad de San Sulpicio de París con la Casa de Misericordia, o Sociedad caritativa de la Ciudad de Victoria, destinado para leer en las Juntas generales que celebró en Bergara la Real Sociedad Vascongada el año 1779", Miscelánea o colección de vario discursos por D. Valentín de Foronda, Madrid, 1793, pp. 24-41.
}

(1742-1795), para su villa solariega de Fernán Núñez en la provincia de Córdoba ${ }^{3}$. Así, por un lado, centraremos nuestra atención en analizar el proceso constructivo de estas tipologías arquitectónicas de carácter comunitario que incorporaron las novedades de la Ilustración, destacando su excepcionalidad por constituir un proyecto muy ambicioso adscrito a la iniciativa personal de un noble en la España de fines del siglo XVIII. Por otro, destacaremos la función simbólica otorgada por el VI conde a estas fundaciones pías, pretendiendo que sus proyectos no solo quedasen reflejados en el ámbito local, sino que fuesen distribuidos entre el mayor público posible, llevando a cabo una estrategia de propaganda personal a través de la palabra y la imagen gracias a El Atlante Español de Bernardo de Espinalt, una obra de gran éxito editorial en la época ${ }^{4}$. Así, estas actividades caritativas ofrecieron un marco idóneo para exhibir la distinción social del conde, ligadas a sus planes de promoción di-

\footnotetext{
${ }^{3}$ Para un análisis biográfico más completo, véase: J. PÉREZ DE GUZMÁN, Embajada del Conde de Fernán Núñez en París a los comienzos de la Revolución Francesa, Madrid, 1910; A. MOUSSET, Un témoin ignoré de la révolution: le comte de Fernan Nuñez, ambassadeur d'Espagne à Paris (1787-1791), París, 1924; J. GUTIÉRREZ, “Un arte de vivir en el siglo XVIII. La carta del sexto Conde de Fernán Núñez", Dieciocho, 6, 1983, pp. 42-60; A. MOREL-FATIO y A. PAZ MELIÁ, "Biografía del conde de Fernán Núñez", en C. J. GUTIÉRREZ DE LOS RÍOS, Vida de Carlos III, Madrid, 1988, vol. II, pp. 331-409; J. CEPEDA ADÁN, “Dos testigos españoles de la Revolución Francesa. El Conde de Fernán Núñez y Pablo de Olavide", en E. DIEGO GARCÍA, J. GUTIÉRREZ ÁLVAREZ, R. CONTRERAS MIGUEL y A. BULLÓN DE MENDOZA (coords.), Repercusiones de la Revolución Francesa en España, Madrid, 1990, pp. 623644; R. PRIETO, La Revolución Francesa vista por el embajador de España, Conde de Fernán Núñez, Madrid, 1997; A. URQUÍZAR HERRERA y J. A. VIGARA ZAFRA, "La nobleza española y Francia en el cambio de sistema artístico, 1700-1850", en L. SAZATORNIL RUIZ y F. JIMÉNO, El arte español entre Roma y París (siglos XVIII y XIX). Intercambios artísticos y circulación de modelos, Madrid, 2014, pp. 258-260.

${ }^{4}$ B. ESPINALT GARCÍA, El Atlante Español ó Descripción general de todo el Reyno de España. Parte segunda, en que se concluye el Reyno de Córdoba, y empieza el de Jaén, Madrid, 1787, vol. XII, pp. 1-63.
} 
plomática y de creación de la memoria familiar. Asimismo, ofreceremos un nuevo perfil de la figura del VI conde, implicado de forma directa en calidad de arquitecto amateur y mecenas de dichas obras pías.

\section{LA POLÍTICA PIADOSA DEL VI CONDE DE FERNÁN NÚÑEZ.}

Las actividades de carácter benéfico constituyeron una práctica habitual entre las élites nobiliarias que persiguieron un doble objetivo con las mismas, por un lado siguieron suponiendo un instrumento de salvación de acuerdo con la tradición de la caridad cristiana y por otro constituyeron un apropiado marco propagandístico para potenciar las virtudes del linaje; teniendo, pues, una doble vertiente religiosa y política. Esta última fue, sin duda, la más ansiada por los miembros de la aristocracia y la oligarquía dirigente. Por ello, en la segunda mitad del siglo XVIII, fue muy común que sufragaran fundaciones pías de manera particular o bien que formaran parte de las elitistas instituciones creadas para erradicar estos problemas sociales ${ }^{5}$.

\footnotetext{
${ }^{5}$ La bibliografía sobre este tema es abundante. Véase, entre otros, P. DEMERSON, “Catálogo de la Socias de honor y mérito de la Junta de Damas Matritense (1787-1811), Anales del Instituto de Estudios Madrileños, $\mathrm{n}^{\mathrm{o}}$ 8, 1972, pp. 120-141; M. V. BARRERA AYMERICH, "Religión y asistencia social en el Antiguo Régimen. Las Mandas Pías de los testadores de Castelló y Borriana durante los siglos XVII y XVIII", Estudios 16. Revista de Historia Moderna, 1980, pp. 115-140; D. PALMA GARCÍA, "Las escuelas patrióticas creadas por la Sociedad Económica Matritense de Amigos del País en el siglo XVIII", Cuadernos de historia moderna y contemporánea, no 5, 1984, pp. 37-56; P. PERNIL ALARCÓN, “Caridad, educación y política ilustrada en el Reinado de Carlos III", Revista de Educación: La Educación en la Ilustración Española, número extraordinario 1988, pp. 343-344; E. LARRIBA, “Las Reales Sociedades Económicas de Amigos del País y la prensa de la Ilustración", en P. AUBERT y J. M. DESVOIS (eds.), Les élites et la presse en Espagne et en Amérique latine: des Lumières à la seconde guerre mondiale, Madrid, 2001, pp. 33-47; C. IBÁÑEZ FERNÁNDEZ, “La integración de la caridad privada en el sistema benéfico del siglo XVIII y su implicación sociopolítica: las obras pías en el País Vasco", en I. REGUERA y R. PORRES (eds.), Poder, pensamiento y cultura en el Antiguo Régimen, San Sebastián, 2002, pp. 157-174.
}

En este contexto, Carlos José Gutiérrez de los Ríos y Rohan-Chabot fue un ejemplo paradigmático de ilustrado. Desde su juventud tuvo una vida itinerante que le llevó a visitar gran parte de España y Europa, mostrando un marcado interés por el arte, la cultura y la ciencia. Los puestos diplomáticos que ocupó durante el último cuarto del siglo XVIII, primero como embajador en Lisboa y luego en París, afianzaron su gusto por el conocimiento artístico y el mundo académico, plasmándolo en los múltiples proyectos que impulsó, dentro de los cuales sobresalieron las reformas arquitectónicas destinadas a la mejora de su villa solariega.

Sin duda, entre dichas reformas, además de la reconstrucción del palacio familiar y el novedoso cementerio extramuros, destacaron las fundaciones asistenciales que bajo la premisa fundamental de mejorar la vida de los habitantes de la villa sirvieron también para modelar su propia imagen pública, permitiéndole exhibir su talante ilustrado. Así, el VI conde desde el año 1762, aún bajo el tutelaje de Francisco de Cepeda, inició una política de obras pías en su villa, aunque, como ha señalado Carolina Blutrach, implícitamente su intención principal fue rehabilitar la figura de su abuelo, el III conde de Fernán Núñez y, por ende, la memoria del clan familiar, continuando con las empresas piadosas que este último no pudo finalizar debido a la falta de liquidez ${ }^{6}$. Asimismo, el VI conde desarrolló también estas actividades piadosas junto a otros nobles en la corte madrileña. Ejemplo de ello fue la financiación del socorro de los pobres del barrio de las Vistillas de Madrid, donde residía, en colaboración con el marqués de la Florida, el obispo de Albarracín y la marquesa viuda de Villafranca ${ }^{7}$.

${ }^{6}$ C. BLUTRACH JELÍN, El III Conde de Fernán Núñez (1644-1721). Vida y memoria de un hombre práctico, Madrid, 2014, pp. 232-238.

${ }^{7}$ En ese mismo barrio, el VI conde de Fernán Núñez financió la escuela de listonería junto al duque de Alba, el duque del Infantado y el marqués de la Florida, véase: P. PERNIL ALARCÓN, “Carlos III, pionero de las escuelas de formación profesional de la mujer: la escue- 
No obstante, no fue hasta 1782 y gracias a la herencia dejada por su hermana, Escolástica Gutiérrez de los Ríos y Rohan-Chabot, duquesa viuda de Béjar ${ }^{8}$, cuando el VI conde decidió llevar a cabo una importante reforma urbana de su villa solariega, que incluyó un sustancial cambio de las políticas asistenciales y docentes practicadas hasta entonces por sus antepasados, pretendiendo así exhibir Fernán Núñez como un ejemplo de moderna villa ilustrada, dotada con una serie de servicios innovadores desde el punto de vista social que mejorarían el bienestar de sus residentes, permitiéndole crear una imagen de sí mismo como buen gestor y, por ende, apto para la función pública, al tiempo que afianzaba el prestigio del linaje.

El propio VI conde dejaba patente sus intenciones al preguntarse sobre el porqué de tales iniciativas, instando a sus descendientes a asumir la responsabilidad que implicaba su posición de grande de España y la importancia de ejercer las obligaciones preceptivas de su condición:

“No estrañaré parezca à algunos temeridad y aun falta de conocimiento y calculo de la vicisitud de los sucesos humanos y de los vicios demasiado comunes en la administracion de los caudales, el contar con la rectitud de esta, por espacio de 136 años para fundar sobre tan inciertos principios, dos establecimientos publicos, cuia notoria utilidad, á lo menos, espero no disputará la critica mas severa. Es cierto que atener en el dia los tres millones de capital que cuento se junten con el tiempo para asegurar su renta, y el caudal necesario para la fabrica de los dos edificios, y gastos de su primer establezimiento pudiendo emplearlos en esto sin perjudicar à mis hijos, lo haria con preferencia á exponerlo al menor de los riesgos que he tenido mui presentes, y a que solo ha

la de listonería del Barrio de las Vistillas de Madrid", Anales del Instituto de Estudios Madrileños, nº 25, 1988, pp. 183-207.

${ }^{8}$ Archivo Histórico Nacional-Sección Nobleza, Toledo (en adelante AHN-SN), Fernán Núñez, Caja 469, Documento 5-9. necesidad indispensable sugeto mi ardiente deseo de ver verificados mis proiectos. Este, mi mismo amor propio, y la natural propension, y gusto que tengo en inventar, y dirigir fabricas utiles al publico, me impediran ciertamente si me fuese posible ceder á otro el entretenimiento de la direccion de la obra, y la gloria de verla establecida por $\mathrm{mi}$, a toda mi satisfaccion y de gozar en mis dias del fruto que me prometo de estos principios. Privado, pues, de toda esperanza en esta parte, no me quedava otro recurso que el de partir con mis succesores esta gloria fiado en que conocerán la que á ellos mismos les resulta, y su obligacion como SSres. del Pueblo y Patronos de estos establecimientos publicos, en llevarlos a su colmo. En mi misma casa subsisten, y hemos pagado gustosos mis predecesores y yo, hace mas de 150 años, otros establecimientos piadosos menos utiles y dotados que este, solo por no faltar a la voluntad de nuestros antecesores, ¿que razon ai, pues, para que yo injurie á mis succesores desconfiando de su exactitud y providad en una cosa que nada deve costarles?"9.

La singularidad de las reformas arquitectónicas llevadas a cabo en la villa de Fernán Núñez radica en que los planos de las mismas fueron diseñados por el VI conde, contando probablemente para su elaboración con la ayuda de su pintor de cámara, Vicente Mariani ${ }^{10}$. Así, el VI conde constituyó una figura singular entre la aristocracia coetánea, no solo por su exhaustivo conocimiento teórico de los nuevos planteamientos arquitectónicos y urbanísticos que se generaron tanto en Europa como en España ${ }^{11}$, tam-

${ }^{9}$ Ibídem, Caja 470, Documento 5.

${ }^{10}$ Vicente Mariani y Todolí fue pintor de cámara del VI conde de Fernán Núñez, acompañándolo en sus embajadas de Lisboa y París. Entre sus atribuciones estaban la de diseñar dibujos y planos, grabar retratos e incluso hacer de amanuense para el conde, véase: Ibídem, Caja 1442, Documento 1.

${ }^{11}$ Antonio Ponz atribuyó al VI conde las innovaciones arquitectónicas aplicadas en el palacio familiar de Fernán Núñez, "efecto sin duda de los conocimientos que dicho Señor ha adquirido en sus largos viajes por Europa", véase: A. PONZ, Viaje de España, en que se da 
bién por las destrezas prácticas exhibidas a la hora de construir el palacio familiar y modernizar las instalaciones agropecuarias de las hazas localizadas en su estado ${ }^{12}$. No en vano, tuvo acceso y participación directa en los debates generados en torno al nuevo estilo clasicista en el seno de la Real Academia de Bellas Artes de San Fernando en calidad de consiliario ${ }^{13}$ y se relacionó personalmente con los adalides del neoclasicismo en España, tales como Antonio Ponz, Diego Antonio Rejón de Silva, Gaspar de Jovellanos, el V marqués de Montehermoso o el III marqués de Ureña, viajando en compañía de este último a París en septiembre de $1787^{14}$. En la misma línea, su biblioteca fue fiel reflejo del citado interés por la nueva arquitectura de corte clasicista, de ahí que aparezcan ejemplares de autores como Vitruvio, Blondel, Milizia o Winckelmann, muy habituales en el mundo académico. Pero, junto a estos, resulta relevante que atesorara obras de carácter muy específico, centradas en los aspectos puramente constructivos, como Los principios de Matemáticas de Benito Bails, el Tratado de Arquitectura Civil de William Chambers o el Manual de Arquitectura de Giovanni Branca, evidenciando hasta qué punto podría conocer las destrezas de la actividad arquitectónica ${ }^{15}$.

Como hemos señalado, el VI conde desarrolló gran parte de su vida alejado de

noticia de las cosas más apreciables, y dignas de saberse, que hay en ella, Madrid, 1792, tomo XVII, p. 152.

12 J. A. VIGARA ZAFRA, "El palacio del VI conde de Fernán Núñez: La arquitectura como exaltación simbólica del linaje durante la Ilustración", Tiempos Modernos: revista electrónica de Historia Moderna, vol. 8, no 29, 2014, consultado el 30 de enero de 2015. URL: http:// www.tiemposmodernos.org/tm3/index.php/tm/article/ view/396/423

${ }^{13}$ C. BÉDAT, Los Académicos y las Juntas, 1752-1808, Madrid, 1982, pp. 120-159.

${ }^{14}$ AHN-SN, Fernán Núñez, Caja 2033, Documento 10.

15 Índice general de los libros de que se compone la Librería del Excmo. Sr. Conde de Fernán Núñez, Biblioteca Nacional de España, Madrid (en adelante BNE), MSS/23039. sus estados. Por este motivo, aunque diseñó cada uno de los proyectos destinados a su villa, tuvo que delegar la construcción y finalización de los mismos en personas de su entera confianza. De este modo, la supervisión directa de las obras recayó sobre el administrador de la villa, Joaquín de Luna, mientras que la dirección de la fábrica de los edificios estuvo a cargo de José Díaz de Acevedo, maestro de obras natural de Écija, que desde la década de los setenta trabajó para el conde en obras de distinta índole, principalmente, acondicionando los cortijos que este tenía en torno a Fernán Núñez ${ }^{16}$.

Sin embargo, como veremos a continuación, gran parte de estas iniciativas quedaron en el papel y nunca llegaron a materializarse de forma tangible. Pese a ello, el VI conde lograría uno de los propósitos fundamentales perseguidos con dichas iniciativas, consistente en publicitar sus obras piadosas entre sus coetáneos gracias a su difusión en El Atlante Español, exhibiendo así su perfil como prohombre ilustrado.

\section{EDUCAR AL POBRE}

La educación de las clases populares constituyó uno de los pilares fundamentales de los gobiernos ilustrados que, al margen de la adecuada instrucción moral y religiosa, buscaron el correcto adiestramiento de una mano de obra cualificada ${ }^{17}$. Una educación pensada en términos económicos que pretendía erradicar el pauperismo y, a su vez, generar riquezas para el Estado. El propio VI conde de Fernán Núñez, como evidenciaría a través de las iniciativas llevadas a cabo en su villa, concibió este tipo de instrucción como la solución más adecuada para educar a los grupos marginales de la sociedad, pese a que su idea de la educación para las élites nobiliarias fuera radicalmente opuesta:

\footnotetext{
${ }^{16}$ AHN-SN, Fernán Núñez, Caja 470, Documento 23.

17 O. NEGRÍN FAJARDO, Educación popular en la España de la segunda mitad del siglo XVIII. Las actividades educativas de la Sociedad Económica Matritense de Amigos del País, Madrid, 1987, pp. 248 y ss.
} 
"El que puede educar á sus hijos en su Casa á su vista, con buenos maestros, logrará muchas ventajas. No hai hospital, por bueno que sea, en que el enfermo esté asistido como en su propia Casa, si tiene medios, pues hai quien continuamente le observe el dia y la noche. Esta observacion continua es la mas útil y necesaria para formar el corazon del Niño, penetrando sus inclinaciones, $\mathrm{y}$ aprovechando de ellas, y aun de sus juegos, para dirigirlos, y enseñarles muchas cosas, jugando"18.

LAS ESCUELAS PÚBLICAS DE NIÑOS Y NIÑAS POBRES DE FERNÁN NÚÑEZ.

De todos los proyectos de carácter piadoso diseñados por el VI conde que implicaron la construcción de un edificio de nueva planta específico para atender las necesidades de los habitantes de su villa, solo las escuelas de niños y niñas pobres llegaron a materializarse, siendo administradas por sus sucesores en el título hasta finales del siglo $\mathrm{XIX}^{19}$. Las motivaciones del conde para implicarse en este proyecto estuvieron en consonancia con la mentalidad ilustrada de la época, pretendiendo dotar a los pobladores de Fernán Núñez de una formación de carácter práctico que redundara en su propio provecho. Así, pese a que ya financiaba dos escuelas gratuitas de primeras letras desde 1769, los recursos económicos adquiridos con la herencia de su hermana posibilitaron que afrontara proyectos más ambiciosos para su villa, en consonancia con los preceptos de la Ilustración, constituyendo las citadas escuelas uno de los principales pilares de su política piadosa en Fernán Núñez:

"Conociendo que el principal beneficio que puede hacerse à un Pueblo es cuidar de la educacion de sus vezinos, y haviendo

${ }^{18}$ C. J. GUTIÉRREZ DE LOS RÍOS, Carta de Don Carlos de los Ríos, XXII Señor y VI Conde de Fernán Núñez, a sus hijos, París, 1791, p. 187.

${ }^{19}$ AHN-SN, Fernán Núñez, Caja 87, Documento 49- visto con mucho dolor de mi corazon desde la primera vez que vine à este el gran numero de niños y niñas que por falta de medios se criavan casi sin idea de religion, siendo un continuo motivo de disgustos, y desazones, la ociosidad en que vivían; procuré desde luego acudir al remedio de este mal estableciendo y pagando una Escuela publica gratuita para niños pobres, y otra igual para niñas en que he tenido consuelo de ver constantemente ocupados mas de 210, cuios progresos he seguido, y premiado con gusto. La cortedad de mis facultades, no me permitió entonces dotar competentemente estos establecimientos ni ponerlos en el pie que deseava: pero haviendome quitado la divina providencia à mi querida Hermana la Duquesa de Bejar, la ultima prueva de su cariño y amistad, me facilitó medios para poder verificar mis deseos, y hacer Fundacion de Escuelas, con casa para ellas, y dotaciones competentes, todo lo qual hago en sufragio de su alma, y bien de mis vasallos"20.

Las nuevas obras del palacio comenzaron en torno a 1783 , pero sabemos que aún a quince de agosto de 1787 las citadas escuelas ni se habían concluido ni se estaban utilizando, aunque cómo él mismo expresaba en su testamento, "los dos edificios de las Escuelas estan al concluir y por aprovechar el terreno se les ha dado una figura semiobalada, con gradas que los hace muy estraños, vistosos, y comodos para que el maestro desde su asiento, que esta enfrente del semicirculo vea todos los movimientos de los muchachos, de modo que parezca un anfiteatro antiguo" $^{21}$.

Resulta, pues, un edificio muy novedoso por su estructura y los aspectos simbólicos del mismo, pensado dentro de la estrategia urbana global concebida para su villa. La singularidad de esta obra residió en insertar en su planta triangular dos semicírculos opuestos entre sí, a modo de gradas

\footnotetext{
${ }^{20}$ Ibídem, Caja 469, Documento 5-4.

${ }^{21}$ Archivo Histórico de Protocolos, Madrid (en adelante AHPM), Protocolo 24.836, fol. 477r.
} 
clásicas de los teatros romanos. Cada uno de estos semicírculos albergó la escuela de niños de un lado y la de niñas del otro, permitiendo que estuvieran totalmente separadas entre sí. Esta estructura de influencia clásica contrastó con la mayoría de las iniciativas llevadas a cabo para recintos docentes de la época que, generalmente, readaptaron edificaciones religiosas para dicho fin $^{22}$, salvo la excepción de los anfiteatros anatómicos en las escuelas de cirugía ${ }^{23}$ (Fig. 1).

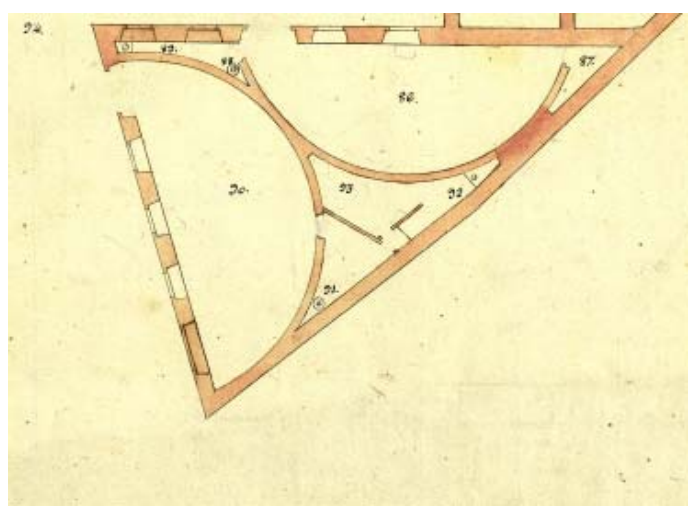

- Fig. 1. Detalle del plano del palacio de Fernán Núñez correspondiente a las escuelas de niños y niñas pobres. Archives Nationales, París (en adelante ANP), N/III/Espagne/2/5, 6, 10, 11/5.

Asimismo, el reglamento aprobado en la fundación de esta obra pía asentó, más si cabe, el protagonismo del VI conde y su familia sobre la villa. En ese sentido, el responsable de la educación en la escuela de niños sería el maestro, elegido entre los sacerdotes de su administración, cuya misión principal consistiría en enseñarles a leer, escribir y contar, al tiempo que los adoctrinaría en los valores de sumisión y agradecimiento a los señores de la Casa. En esta misma línea, cabe resaltar la unión simbólica de las escuelas con el nuevo palacio familiar, al que debían acudir para rezar el Rosario en la capilla de Santa Escolástica todos los domingos y días

${ }^{22}$ R. M. AÑÓN ABAJAS, La arquitectura de las escuelas de primarias municipales de Sevilla hasta 1937, Sevilla, 2005.

${ }^{23}$ A. RODRÍGUEZ GUTIÉRREZ DE CEBALLOS, El siglo XVIII: Entre tradición y academia, Madrid, 1992, pp. 29-30. festivos ${ }^{24}$, obsequiándolos también con una merienda anual en el jardín del palacio, donde se escenificaba la caritas señorial a través de los hijos del VI conde, quienes se encargaban de repartir los alimentos entre los niñas y niñas pobres ${ }^{25}$.

Esta exhibición pública de la caridad señorial tendría su cénit en la ceremonia de entrega de premios a los mejores estudiantes de la escuela de niños, recibiendo esta gratificación de manos del titular de la Casa en presencia de las autoridades civiles y eclesiásticas de la villa ${ }^{26}$, mientras que el premio de las niñas consistiría en una dote para el matrimonio de 2.208 reales de vellón, haciéndose efectiva en el ceremonial de los desposorios que se desarrollaría en la capilla de Santa Escolástica en presencia del patrono y de todos los niños y niñas de las escuelas que acompañarían el cortejo nupcial ${ }^{27}$.

\section{LA CASA DE EDUCACIÓN DE NI- ÑA HUÉRFANAS DE SANTA ESCO- LÁSTICA}

Sin embargo, estas iniciativas no colmaron las expectativas del VI conde. Así, en septiembre de 1785, comunicó a su abogado, Antonio Salcedo, la firme pretensión de crear un centro de enseñanza de nueva planta dedicado a la figura de su hermana, cuyo objetivo principal sería la educación práctica de las niñas huérfanas de la villa. La creación de esta casa de educación obsesionó durante varios años al VI conde que para su confección adquirió publicaciones sobre instrucción pública ${ }^{28}$, mandó copiar reglamen-

\footnotetext{
${ }^{24}$ AHN, SN, Fernán Núñez, Caja 469, Documento 5-4.

${ }^{25}$ AHPM, Protocolo 24.836, fol. 477r.

${ }^{26}$ AHN-SN, Fernán Núñez, Caja 469, Documento $5-4$.

${ }^{27}$ Ibídem.

${ }^{28}$ El VI conde de Fernán Núñez se interesó por la problemática de la instrucción pública, adquiriendo obras de autores como François Fénelon o Pedro Rodríguez de Campomanes, véase: Índice general de los libros de que se compone la Librería del Excmo. Sr. Conde
} 
tos de instituciones educativas coetáneas ${ }^{29} \mathrm{e}$ incluso requirió informes sobre los centros educativos de Córdoba con el fin de proyectar la casa de educación más avanzada de la provincia $^{30}$.

El acta de fundación de esta obra pía evidenció el carácter eminentemente práctico de la misma, proyectando una casa de educación destinada a la enseñanza laica de doce niñas huérfanas con el objetivo primordial de criar buenas madres de familias ${ }^{31}$. Igualmente, esta casa de educación se integraría dentro de la reforma urbana efectuada en la plaza de armas del palacio familiar, sustituyendo al edificio del mesón, localizado frente a la escuela pública de niñas pobres, permitiendo a la maestra dirigir ambos recintos al unísono con la ayuda del capellán de la Casa, una segunda maestra, una ayudanta, dos cocineras, una lavandera, una portera y una moza de barrer ${ }^{32}$.

El diseño de esta casa de educación asumió los conceptos arquitectónicos más novedosos formulados para este tipo de instituciones ${ }^{33}$. Diseñado como un recinto autónomo, constaría de dos plantas articuladas en torno a un gran patio central y un amplio jardín lateral, que permitirían iluminar ade-

de Fernán Núñez, BNE, MSS/23039, fols. 219r, 223v, 224r, 225 r y 240 r.

${ }^{29}$ El interés del VI conde de Fernán Núñez por adquirir las actas fundacionales de otras instituciones docentes debemos ponerlo en relación con su intención por perfilar de forma correcta el reglamento de su escuela. Para ello, se fundamentó en tres modelos de centros de enseñanza coetáneos: el propuesto por el conde de Vimieiro en la villa de Estremoz, el del duque de Alba en la villa de El Carpio y la casa de educación de niñas huérfanas de la ciudad de Córdoba, véase: AHNSN, Fernán Núñez, C. 470, D. 9-2, 3, 4 y 5.

${ }^{30}$ Ibídem, Documento 27-7, 11 y 18.

${ }^{31}$ Ibídem, Documento 29-13.

${ }^{32}$ Ibídem, Documento 11-1.

33 Hemos localizado el plano correspondientes a la primera y segunda planta del proyecto de escuelas de niñas huérfanas de Santa Escolástica, véase: Archives Nationales, París (en adelante ANP), N/III/Espagne/2/12. cuadamente todo el recinto. Así, atendiendo a las recomendaciones de salubridad en edificios públicos ${ }^{34}$, establecería las habitaciones de las niñas y maestras en el piso superior con el objeto de dotarlas de una mejor ventilación. Para las niñas de menor edad se habilitaría una gran sala común para su instrucción con camas separadas mediante biombos de dos varas de altura y comunicadas directamente con la alcoba de la ayudanta, mientras que las niñas mayores tendrían cuartos individuales con una cama, un par de sillas, una mesa con cajón y un cofre para la ropa ${ }^{35}$. Por su parte, los espacios utilitarios se localizarían en la planta baja, constando de almacenes, lavandería, despensa, cocina, pieza para amasar pan con su horno, gallinero, retretes, portería y comedor para las niñas grandes con dos grandes mesas ovaladas. De este modo, estas dependencias permitirían el autoabastecimiento del edificio y la correcta instrucción de las niñas en las principales labores domésticas (Fig. 2).

Qué duda cabe que junto a la educación de las huérfanas, el VI conde tuvo muy en cuenta el carácter simbólico de esta obra piadosa y así lo reflejó en la escritura fundacional de la misma, de tal forma que le permitiera exhibir su piedad y la de su hermana, en cuyo nombre se levantaría este establecimiento. Claro ejemplo de ello, las alumnas serían obsequiadas con una pequeña medalla de plata con la imagen de Santa Escolástica en un lado y el escudo de los Ríos en el otro, teniendo la obligación de portarlas cuando salieran del recinto de la escuela y, posteriormente, exhibirlas durante sus vidas como señal de agradecimiento a sus patronos $^{36}$.

Desgraciadamente, los problemas financieros del VI conde imposibilitaron la

${ }^{34}$ M. G. JOVELLANOS, "Acerca de la situación y división de los hospicios con respecto a su salubridad", Obras publicadas e inéditas de Don Gaspar Melchor de Jovellanos, Madrid, 1859, tomo II, pp. 432-433. $29-13$

${ }^{35}$ AHN-SN, Fernán Núñez, Caja 470, Documento

${ }^{36}$ Ibídem. 


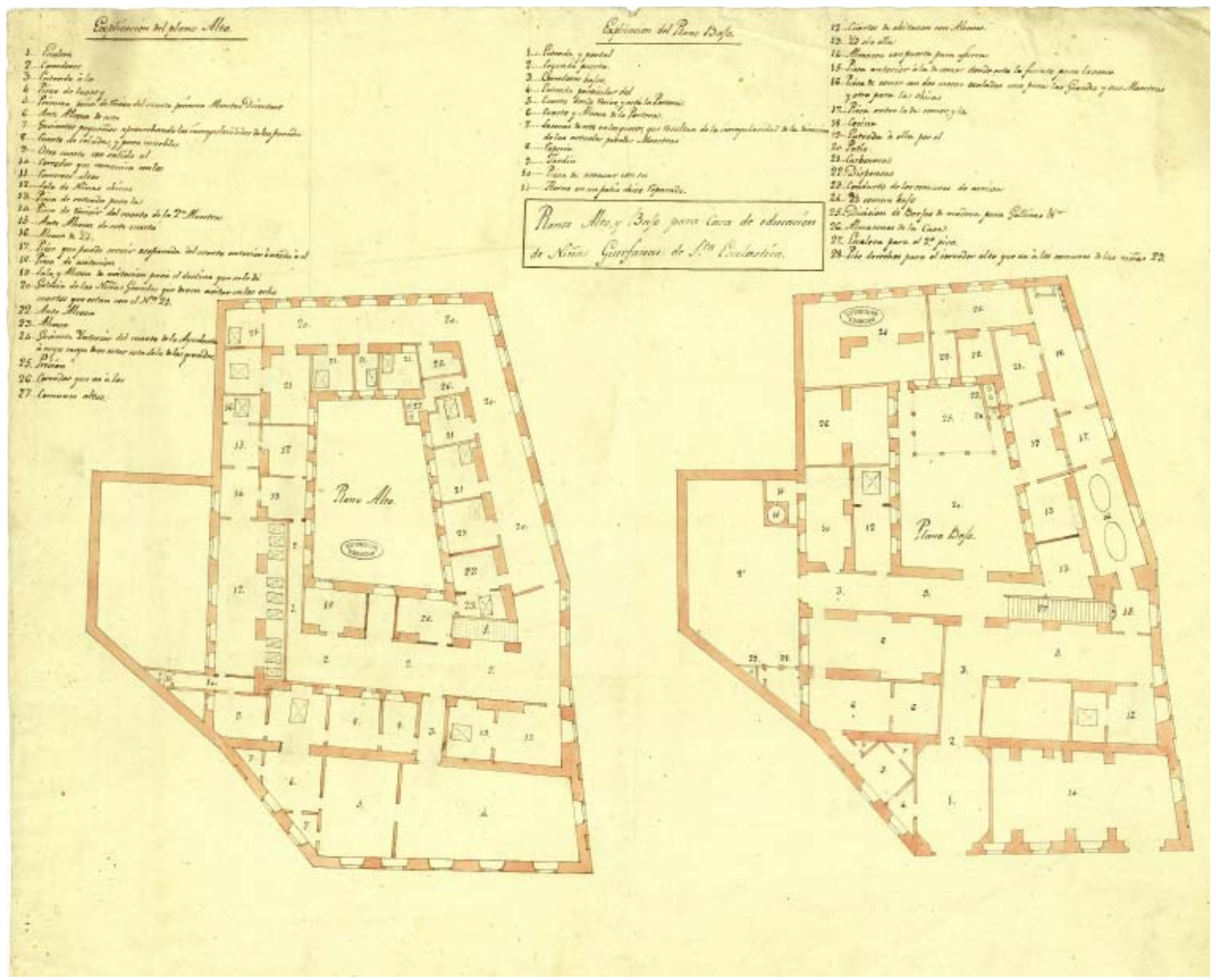

- Fig. 2. Plano de la Casa de Educación de Niñas Huérfanas de Santa Escolástica en Fernán Núñez. ANP, N/III/Espagne/2/12.

consecución de estas obras que, como hemos señalado, tenía minuciosamente diseñadas. Pese a ello, suponen una buena muestra de hasta qué punto sus proyectos estuvieron en consonancia con las novedades docentes de la Ilustración.

\section{CURAR AL POBRE}

Al margen de proporcionar una instrucción correcta a los residentes en su villa, la otra gran preocupación del VI conde de Fernán Núñez fue la de solucionar los problemas sanitarios de su villa. En ese sentido, se mostró en consonancia con las medidas sanitarias llevadas a cabo por la administración de Carlos III, que entendieron en clave política la importancia del factor demográfico y su incidencia en la economía del país. Por este motivo, se promulgaron leyes que promovieron la creación de grandes establecimientos caritativos como hospicios y hospitales para acoger a esa gran masa de marginados e impedidos. Asimismo, pretendieron atajar el vergonzoso problema de los expósitos, que tantos sentimientos de culpa generaron entre las élites sociales y eclesiásticas del país, adoptando como solución principal la habilitación de inclusas convenientemente acondicionadas para la recepción y crianza de estos niños, dotándolas con un número suficiente de amas de cría para el sustento de los citados expósitos ${ }^{37}$.

\footnotetext{
${ }^{37}$ La bibliografía sobre este tema es abundante. Véase, entre otros: L. C. ÁLVAREZ SANTALÓ, Marginación social y mentalidad en Andalucía Occidental. Expósitos en Sevilla (1613-1910), Sevilla, 1980; M. P. FUENTE GALÁN, “La situación de las inclusas en el siglo XVIII. La encuesta de 1790", Chronica Nova, 24, 1997, pp. 61-78; M. P. FUENTE GALÁN, "Ilegitimidad y abandono en la
} 
El VI conde no fue una excepción en ese sentido y, como difundió detalladamente en El Atlante Español, pretendió crear un hospicio y un hospital para enfermos pobres y fundar un socorro para niños expósitos ${ }^{38}$, que aminoraran la alta tasa de mortalidad de la época, al tiempo que le permitieran presentarse ante la sociedad como un ejemplo de benefactor ilustrado, interesado por el bienestar de los residentes en su villa.

\section{EL MALOGRADO PROYECTO DE HOSPICIO Y HOSPITAL DE LA CA- RIDAD.}

A partir de marzo de 1784, el VI conde comenzó a interesarse por la construcción de un hospital y una casa de expósitos en su villa. Por ello, desde su embajada en Lisboa efectuó múltiples consultas a sus agentes en Córdoba con el objetivo de adquirir información sobre los hospitales de la provincia y los cauces administrativos a seguir para levantar la citada obra, pretendiendo fundar una institución que constituyera un referente en materia sanitaria ${ }^{39}$. Sin embargo, no fue hasta abril de 1786 cuando tomó la decisión de reedificar el antiguo hospicio de La Caridad de Fernán Núñez por constituir la solución más viable desde el punto de vista económico y, especialmente, por contar con una iglesia de gran devoción en la villa ${ }^{40}$.

Así, en octubre de 1786, el VI conde comunicó a Andrés Sánchez Torés, vicario de la villa, que el antiguo hospicio de La Caridad estaba inservible, teniendo ya proyectada una completa remodelación del

Granada del siglo XVIII: Un establecimiento para partos de expósitos ilegítimos", Chronica Nova, 27, 2000, pp. 9-21; M. P. FUENTE GALÁN, “Niños expósitos y amas de cría. Las amas como un fracasado sistema de supervivencia de los niños expósitos (S. XVIII)", Publicaciones de la Facultad de Educación y Humanidades del Campus de Melilla, no 31, 2001, pp. 53-66.

${ }^{38}$ B. ESPINALT GARCÍA, Op. cit., pp. 49-63.

${ }^{39}$ AHN-SN, Fernán Núñez, Caja 470, Documento $1-2$ y 3 .

${ }^{40}$ Ibídem, Documento 18-3 y Documento 27-13. mismo $^{41}$. Además, con el objetivo de obtener el control efectivo en materia sanitaria y funeraria de su villa, instó al citado vicario para que negociara la creación de una nueva hermandad piadosa con los miembros del ayuntamiento, cuyo patronato recaería en el titular de la Casa:

"Para esto es necesario que por la villa se me represente el estado en que se halla y la necesidad de remediarlo por medio de un nuevo establecimiento util, en los terminos que yo lo crea mas conveniente à cuio fin con permiso del Señor Obispo, ceden desde luego a mi Casa el Patronato para siempre, á fin de que arreglandolo yo todo del modo que crea mas conveniente, haga de un respetable esqueleto expuesto a su ruina, una fundacion util a aquellos vecinos, á que estan todos prontos a contribuir con sus limosnas, y asistencia personal, siempre que se erigiere nueva Hermandad para alivio de los pobres. Mi proiecto es verificar la obra del cimenterio de Sn. Sebastian, y reuniendole a la Caridad [hospital], establecer una Hermandad util de caridad de que el Señor de la Casa seria el Hermano mayor nato, distinguiendolo de modo que dandose la mano estos dos caritativos establecimientos, se cuidasen a prosperar reciprocamente" ${ }^{\prime \prime 2}$.

En efecto, la debilidad económica del concejo propició que se aceptaran cada una de las cláusulas impuestas por el VI conde, aumentando así su poder efectivo sobre la villa ${ }^{43}$. De este modo, refundó la antigua hermandad de las Ánimas, bajo la nueva denominación de hermandad de La Caridad, integrando en esta fundación tanto la reforma del hospicio y hospital homónimos como la construcción del futuro cementerio consagrado a San Sebastián. Lo interesante del nuevo reglamento de la citada hermandad radicó en la concentración de poder ab-

${ }^{41}$ El hospicio de La Caridad fue abandonado tras la muerte del III conde de Fernán Núñez, pese al intento frustrado de rehabilitarlo por parte del concejo de la villa en 1753, véase: Ibídem, Caja 184, Documento 17.

\footnotetext{
${ }^{42}$ Ibídem, Caja 470, Documento 1-4.

${ }^{43}$ Ibídem, Documento 10-5.
} 


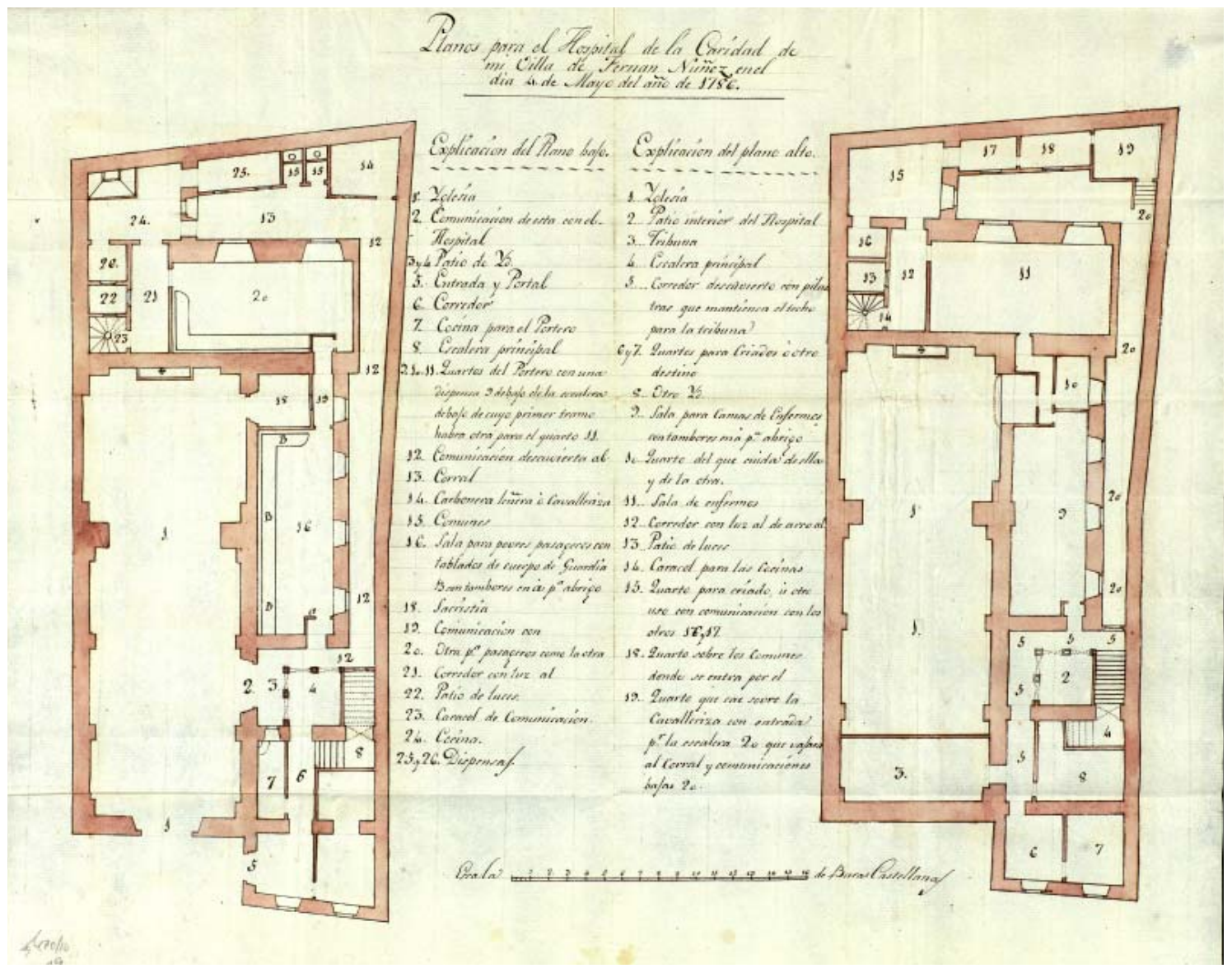

- Fig. 3. Plano para el Hospital de La Caridad de mi villa de Fernán Núñez en el día 4 de mayo de 1786. AHNSN, Fernán Núñez, C. 470, D. 10-9.

soluto en materia asistencial y funeraria en manos de los titulares del linaje, excluyendo taxativamente las injerencias de cualquier autoridad eclesiástica o secular ajena a la propia institución. Así pues, dicha hermandad estuvo presidida por el señor de la Casa y completada por una serie de consiliarios elegidos entre las principales personalidades de la villa, organizando las pertinentes juntas mensuales en la sacristía de la capilla de Santa Escolástica en el palacio familiar. Entre las principales atribuciones de la hermandad estuvo la gestión del hospital y la coordinación del ritual de enterramiento de los vecinos de Fernán Núñez en el novedoso cementerio extramuros, donde el VI conde escenificaría una prueba más de la piedad familiar al enterrar a su costa a los pobres de la villa ${ }^{44}$.

\footnotetext{
${ }^{44}$ Ibídem, Documento 8.
}

Tras la fundación de la citada hermandad, el VI conde remitió a su administrador, Joaquín de Luna, el plano para la reforma del hospicio y hospital de La Caridad que él mismo diseñó ${ }^{45}$. Con este primer proyecto de reedificación pretendía remodelar completamente el antiguo hospicio y las casas aledañas a este, respetando al máximo las trazas de la iglesia de La Caridad. De este modo, ubicaría el hospicio en la planta baja con dos grandes salas para albergar a los viajeros, además de todas las dependencias utilitarias como la cocina, la despensa, los cuartos del portero, la carbonera y los comunes. Mientras que en la planta superior se localizaría

\footnotetext{
${ }^{45}$ Hemos localizado el plano del primer proyecto de reforma del antiguo hospicio de La Caridad en el Archivo Histórico Nacional de Toledo, véase: Ibídem, Documento 10-9.
} 
el hospital con dos grandes salas para los enfermos (Fig. 3).

A pesar de que en este diseño no tuvo en cuenta las novedades que se estaban publicando en materia de salubridad e higiene para centros comunitarios, el VI conde decidió seguir adelante con la reforma, encargándosela a José Díaz de Acevedo. Este, tras reconocer el edificio en noviembre de 1786, efectuó un detallado presupuesto de la reedificación tasada en 35.240 reales de vellón, junto a unas instrucciones muy concisas sobre el proceso de remodelación que se debía llevar a cabo ${ }^{46}$. Sin embargo, este primer proyecto de reconstrucción del antiguo hospicio de La Caridad fue abandonado como consecuencia de las costosas obras del palacio familiar y de las dudas del VI conde sobre la salubridad y titularidad del mismo ${ }^{47}$.

\section{EL HOSPITAL, HOSPICIO Y CASA DE NIÑOS EXPÓSITOS DE LA CARIDAD}

En diciembre de 1786, el VI conde cambió su idea primigenia del hospital gracias a los consejos de su confesor, el padre Miguel de Espejo. Por un lado, desestimó el primer proyecto de reedificación del antiguo hospital de La Caridad por emplazarse en el centro del pueblo, en un espacio donde desembocaban las aguas de las calles, quedando estancadas en su inmediaciones, "constituiendo suelo contrario a Casa de Sanidad: a lo que se agrega carecer de ventilarios los hospitales situados dentro de poblacion; que sosteniendo cuerpos enfermos en las primeras superficies, son mas perjudiciales al publico, que las sepulturas de iglesia" ${ }^{48}$. Por otro, consideró la idea de erigir un hospital de nueva fábrica a las afueras de la villa, mejorando las condiciones de salubridad del mismo y evitando las injerencias del obispado cordobés sobre el patronato de la obra pía ${ }^{49}$.

\footnotetext{
${ }^{46}$ Ibídem, Documento 10-8.

${ }^{47}$ Ibídem, Documento 3-9.

${ }^{48}$ Ibídem, Documento 16-1.

${ }^{49}$ Ibídem, Documento $16-4$ y 5.
}

Por estos motivos, el VI conde decidió realizar la fundación del nuevo hospicio y hospital de La Caridad en dos fases cronológicas bien diferenciadas, que le permitieran habilitar convenientemente un edificio de nueva fábrica extramuros de su villa. Así, en una primera fase, volvería a considerar la remodelación del antiguo hospicio y hospital de La Caridad, pero con un diseño que tuviera en cuenta los principios de salubridad aplicados a este tipo de edificios, que se "hará desde luego con parte de los 70.000 reales de que trata el articulo el reparo preciso, tanto para que no se arruine y tenga mejor acogida que en el dia los pobres transeuntes, como para que en caso necesario de una epidemia puedan si se creiese conveniente, y huviese suficiente fondo para hacerlo, recogerse y cuidarse alli provisionalmente los pobres mas necesitados y faltos de ausilio en sus $\operatorname{casas}^{\prime \prime 50}$. Mientras que en una segunda fase, se efectuaría un hospital de nueva fábrica a las afueras de la villa, cuya construcción y mantenimiento tasó en 166.229 reales de vellón, contando con la dotación de un capellán, tres practicantes, tres enfermeras, un médico, un cirujano y un portero ${ }^{51}$.

El VI conde fue madurando estos proyectos a lo largo de 1787, junto a su interés por crear una fundación de casa de niños expósitos, que financiaría con 3.300 reales de vellón anualmente ${ }^{52}$. Esta fundación estaría dotada con diez amas de cría que mantendrían a los niños hasta que fueran destinados a las casas de expósitos de Córdoba ${ }^{53}$. Así pues, el VI conde, ciñéndose a la primera fase de este proyecto, decidió rediseñar el plano para el antiguo hospital de La Caridad, integrando en dicho establecimiento un hospicio, un hospital y una casa para niños expósitos.

Ibídem, Documento 7.

${ }^{51}$ Ibídem, Documento 7-8.

${ }^{52}$ Ibídem, Documento 27-13.

53 S. GÓMEZ NAVARRO, "Los nombramientos de obras pías: Las obligaciones de expósitos a través de la documentación notarial cordobesa en la segunda mitad del siglo XVIII", Ámbitos, nº 3, 2000, pp. 29-34. 
Los nuevos planos diseñados por el VI conde evidencian la mejora de las condiciones sanitarias y de ventilación del establecimiento gracias a dos grandes patios interiores y un jardín en la parte posterior del edificio. En la planta baja, además del hospicio con una sala para albergar hombres, una cocina y una serie de dependencias de carácter administrativo, se establecería junto a la entrada un torno para dejar los niños expósitos con comunicación directa con el cuarto de la portera ${ }^{54}$. Mientras que en la planta alta, se ubicaría el hospital con dos salas separadas, una para hombres y otra para mujeres, los cuartos de los practicantes y las enfermeras, y un cuarto reservado para los partos secretos de los expósitos. En este mismo piso se instalaría la sala para las mujeres del hospicio y un cuarto privado con acceso a las tribunas de la iglesia que sería para uso restringido del fundador $^{55}$, siguiendo así el modelo de hospital de Dax, descrito pormenorizadamente por el VI conde en su diario de viajes ${ }^{56}$ (Figs. 4 y 5).

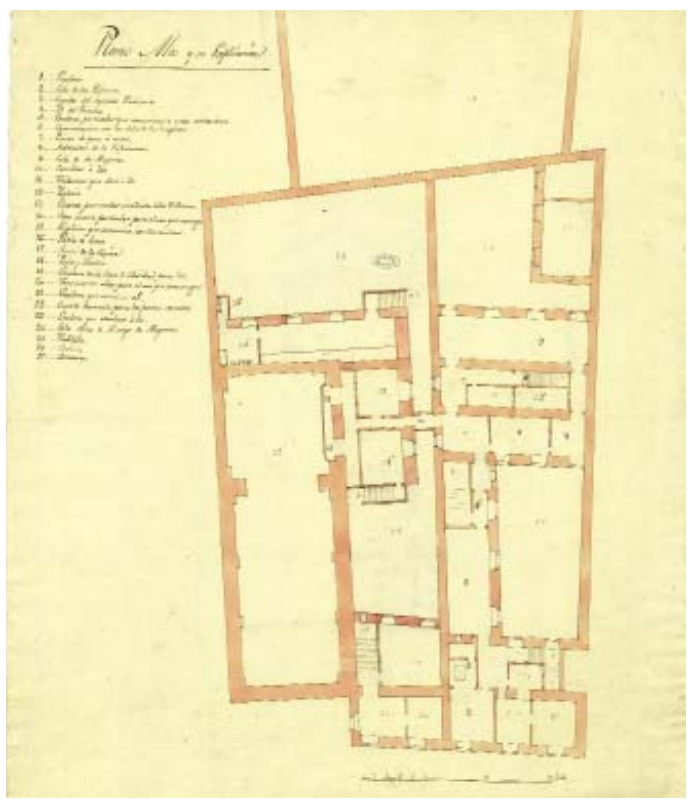

${ }^{54}$ AHN-SN, Fernán Núñez, Caja 469, Documento 7.

${ }^{55}$ Los dos planos correspondientes a la primera y segunda planta del definitivo proyecto de reforma del antiguo hospital de la Caridad, véase: ANP, N/III/Espagne/2/8-9.

${ }^{56}$ AHN-SN, Fernán Núñez, Caja 2033, Documento 10-2, fols. 22r.v. y 23 r.

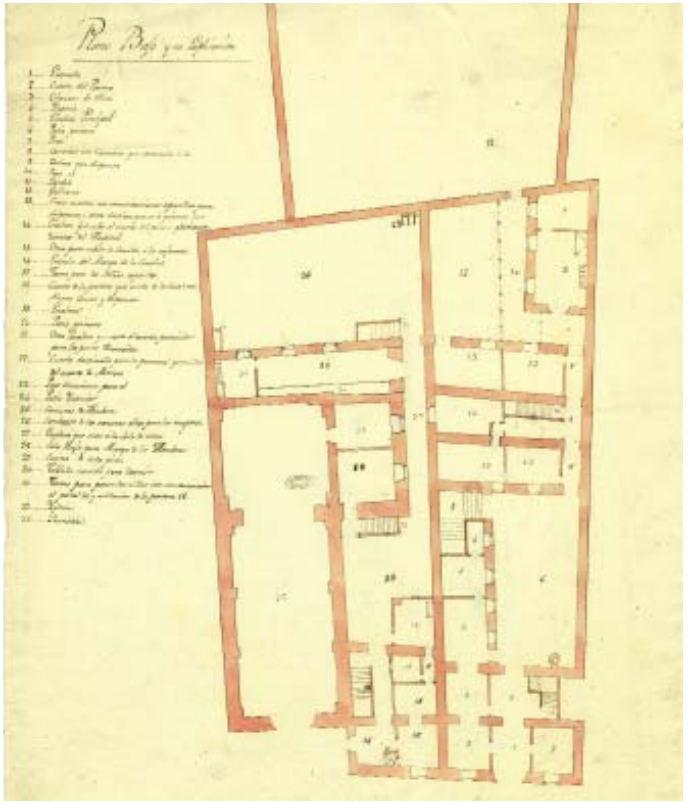

- Figs. 4 y 5. Planos del piso alto y bajo del Hospital y Hospicio de La Caridad. ANP, N/III/Espagne/2/8-9.

Con respecto al desarrollo de las obras, sabemos que en mayo de 1787 aún no se habían finalizado ${ }^{57}$, pero los restos que han quedado del establecimiento y la documentación conservada al respecto, nos indican que el edificio debió concluirse a finales de ese mismo año $0^{58}$. Sin embargo, la ambiciosa construcción del hospital de nueva fábrica equipado con las novedades sanitarias de la época, como veremos más adelante, solo quedó reflejada en las páginas de El Atlante Español, no llegando a materializarse en los siguientes treinta y cuatro años tal como preveía el acta de fundación ${ }^{59}$, pese a que en la citada publicación se daba por hecho la inmediata construcción del citado edificio, cuyo terreno estaba ya marcado y los planos finalizados ${ }^{60}$.

\section{HOSPEDAR AL VIAJERO}

Durante la segunda mitad del siglo XVIII, con la paulatina mejora de los siste-

\footnotetext{
${ }^{57}$ Ibídem, Caja 470, Documento 11-1.

${ }^{58}$ AHPM, Protocolo 24.836, fol. 478r.

${ }^{59}$ AHN-SN, Fernán Núñez, Caja 469, Documento 5-9.

${ }^{60}$ B. ESPINALT GARCÍA, Op. cit., pp. 50-63.
} 
mas de comunicaciones y el auge de la cultura del viaje, uno de los de edificios de carácter comunitario que se reguló con el fin de mejorar sus condiciones de habitabilidad fue el mesón, codificándose una serie de requisitos mínimos para el hospedaje de los viajeros $^{61}$.

En ese sentido, proliferaron múltiples estudios relativos a la morfología y función de los espacios que debían articular esta tipología arquitectónica. Para el caso español destacó el Tratado legal y político de caminos públicos y posadas, escrito por el abogado valenciano Tomás Manuel Fernández de Mesa en $1756^{62}$, texto de marcada influencia francesa, donde se especificó cada una de las condiciones arquitectónicas que debían cumplir estos edificios, teniendo un marcado influjo sobre los mesones de nueva planta construidos en la segunda mitad del siglo XVIII ${ }^{63}$.

El VI conde, siguiendo la política de mejoras en los edificios comunitarios de su villa, decidió dotarla con unos mesones que cumplieran con los principios arquitectónicos e higiénicos de la Ilustración. Para ello, como reflejó en sus proyectos, tuvo muy en cuenta las instrucciones del citado Tomás Manuel Fernández de Mesa, las cuáles conocía detalladamente, no en vano atesoraba un ejemplar del citado tratado en su biblioteca ${ }^{64}$.

${ }^{61}$ B. BLASCO ESQUIVIAS, "Los espacios de la necesidad: alimentación, higiene y descanso nocturno", en B. BLASCO ESQUIVIAS (dir.), La casa. Evolución del espacio doméstico en España, Madrid, 2006, vol. I, pp. 43-46.

${ }^{62}$ T. M. FERNÁNDEZ DE MESA, Tratado legal y político de caminos públicos y posadas. Parte II, que trata de las posadas, Valencia, 1756

${ }^{63}$ M. PÉREZ SÁNCHEZ, "Arquitectura civil en Murcia bajo la Ilustración: el Parador del Rey", Murgetana, no 86, 1993, págs. 71-79; L. GARCÍA BLÁNQUEZ, M. MUÑOZ CLARES y J. A. SÁNCHEZ PRAVIA, “La antigua Posada de Librilla", Revista Murciana de Antropología, no 13, 2006, pp. 133-157.

${ }^{64}$ Índice general de los libros de que se compone la Librería del Excmo. Sr. Conde de Fernán Núñez, BNE, MSS/23039, fol. 226r.

\section{EL MESÓN DE LA PLAZA DE ARMAS DEL PALACIO DEL VI CONDE DE FERNÁN NÚÑEZ}

La villa de Fernán Núñez contaba con un antiguo mesón del siglo XVII adquirido por el III conde de Fernán Núñez en $1689^{65}$, localizándose en las inmediaciones del hospicio de La Caridad, aunque desconocemos su estructura original ${ }^{66}$. No obstante, pese a la existencia de este mesón, el VI conde decidió construir otro de nueva fábrica, mejor acondicionado e instalado en la plaza de armas del palacio, sede del poder familiar. Este edificio se insertó así dentro del plan de mejoras urbanísticas de la villa, constituyendo un antecedente de las reformas arquitectónicas que se efectuarían en el citado palacio en la década de 1780 . Las obras se iniciaron en 1766, sin contar aún el VI conde con la mayoría de edad, y finalizaron con anterioridad al primer proyecto de reforma del palacio proyectado por Joaquín de Luna en 1776 , constituyendo la primera intervención de estilo clasicista de las efectuadas en la villa de Fernán Núñez ${ }^{67}$ (Fig. 6).

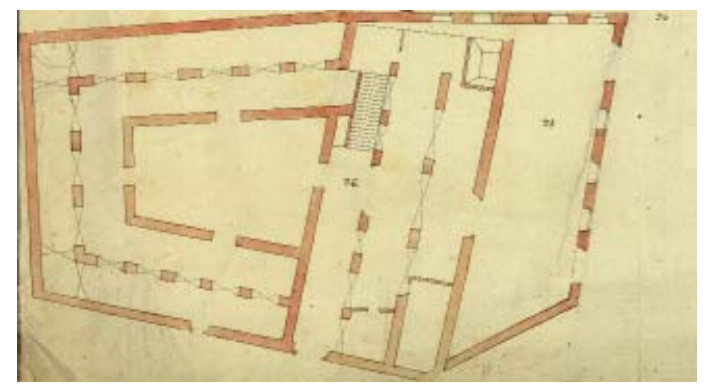

- Fig. 6. Detalle del plano del palacio de Fernán Núñez correspondiente al mesón. ANP, N/III/ Espagne/2/5, 6, 10, 11/5.

Aunque ignoramos la autoría de esta primera intervención, conocemos parte de su estructura original gracias al plano de la planta baja del palacio efectuado por el VI conde, revelando que contaba con múltiples

${ }^{65}$ AHN-SN, Fernán Núñez, Caja 471, Documento 5-1.

${ }^{66}$ Ibídem, Caja 470, Documento 18-1 y 2.

${ }^{67}$ Ibídem, Documento 28. 
cuartos en torno a un patio central porticado, además de un gran almacén para uso del palacio junto a la entrada ${ }^{68}$. De hecho, fue el edificio más ponderado por Juan García y Castro en la primera descripción de la villa efectuada para El Atlante Español en 1781:

"Estan tambien contiguas a esta plaza las casas meson balconeado todo de maravillosa estructura, con multiplicidad de quartos, todo con mucha capacidad que lo hazen mas hermoso, con una fuente de llabe para la maior combeniencia, costeado, como tambien la fuente de la plaza por los $\mathrm{S}^{\text {res. }}$. Condes de esta villa como tan cuidadosos en las comodidades de todos, i en especial en las utilidades de su pueblo, cuio conjunto de cosas tan diestramente preparadas, hazen la mas harmoniosa vista a esta plaza" ${ }^{69}$.

No obstante, a partir de 1783, con las obras de reconstrucción del palacio familiar, el VI conde decidió transformar gran parte del mesón para adaptarlo a la estética del conjunto palaciego. Todo ello, pese a que cómo se indicó en El Atlante Español su primera intención era construir la escuela de niñas huérfanas de Santa Escolástica en el solar que ocupaba dicho mesón ${ }^{70}$. Pero, ante la imposibilidad para afrontar tales gastos, decidió remodelarlo, encargando los planos a José Díaz de Acevedo en mayo de 1787. Estos manifiestan con claridad que el objetivo principal de la reforma fue presentar a los huéspedes una visión más moderna de la villa, mediatizada en su conjunto por el poder de los Fernán Núñez a través de su palacio ${ }^{71}$. Para ello, remodelaron las ventanas y gradas de la fachada del mesón que daban a la plaza de palacio, homogeneizando la decoración exterior con la del conjunto palatino, al tiempo que efectuaron una serie de cambios en su estructura interior con el fin de mejorar de habitabilidad del mismo (Figs. 7 y 8).

\footnotetext{
${ }^{68} \mathrm{ANP}, \mathrm{N} / \mathrm{III} /$ Espagne/2/5, 6, 10, 11/5.

${ }^{69}$ AHN-SN, Fernán Núñez, Caja 184, Documento 17.

${ }^{70}$ B. ESPINALT GARCÍA, Op. cit., p. 3.

${ }^{71}$ AHN-SN, Fernán Núñez, Caja 470, Documento $27-16$ y 17.
}
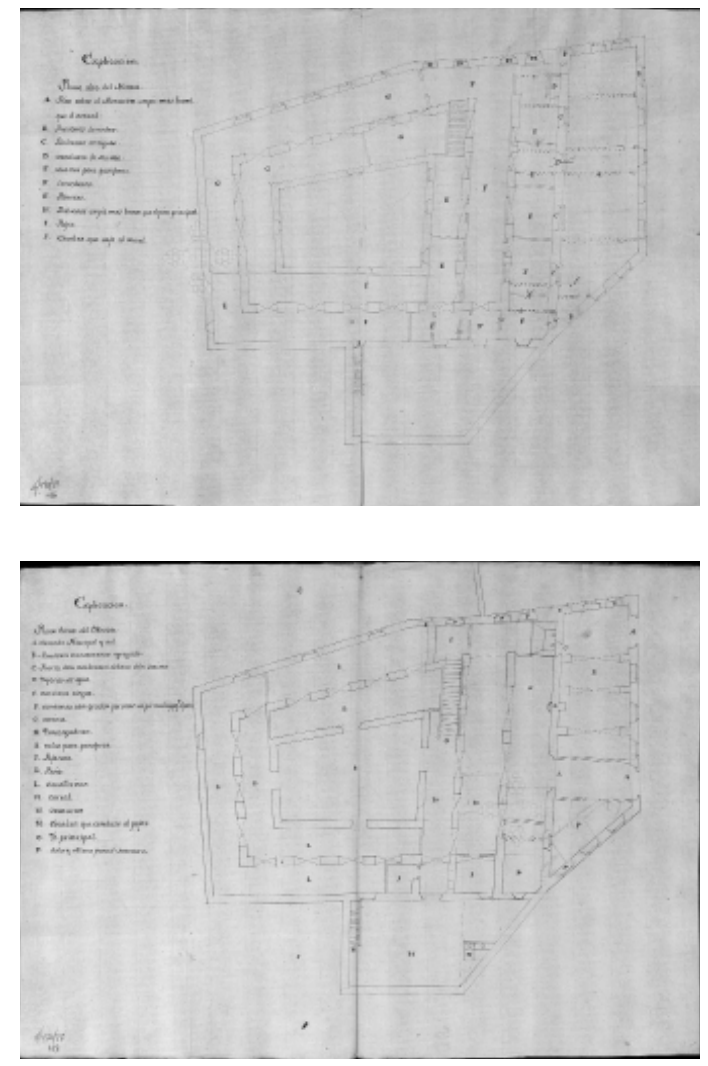

- Figs. 7 y 8. Planos del piso alto y bajo del mesón de Fernán Núñez. AHN-SN, Fernán Núñez, C. 470, D. 27-16 y 17.

\section{EL MESÓN DE LA PLAZA DE SAN MARCOS: EJEMPLO DE HOSPEDAJE DE LA ILUSTRACIÓN}

Pese a lo remozado que quedó el mesón de la plaza de palacio, el VI conde pretendió instalar un nuevo edificio que contara con las principales innovaciones arquitectónicas de la Ilustración. Así, en junio de 1787, a través de su administrador, Joaquín de Luna, compró una serie de casas pertenecientes al capitán Serrano en la plaza de San Marcos con el fin de ubicar en estos terrenos el nuevo mesón ${ }^{72}$.

El VI conde dejó finalizados los planos a su marcha a la embajada de París ${ }^{73}$, aunque solo conocemos la planta del piso superior ${ }^{74}$.

\footnotetext{
${ }^{72}$ Ibídem, Documento 11-1.

${ }^{73}$ Ibídem, Documento 29-13, fol. 8v.

${ }^{74} \mathrm{ANP}, \mathrm{N} / \mathrm{III} /$ Espagne/2/14.
} 
Este diseño muestra con claridad que siguió las directrices del tratado de Fernández de Mesa. Así pues, tenía previsto habilitar dos grandes atrios que permitieran ventilar e iluminar las dependencias interiores, y un corral en uno de los extremos del edificio. Asimismo, ubicaría el pajar justo encima de las caballerizas con los conductos que permitieran bajar la paja desde el piso superior, además de una serie de habitaciones para guardar los equipajes. Pero la innovación más destacable fue la diferenciación social establecida en los cuartos de los huéspedes, ya que de los veinte cuartos disponibles en la planta alta, solo cinco de ellos tendrían alcoba, destinándose a personalidades distinguidas ${ }^{75}$ (Fig. 9).

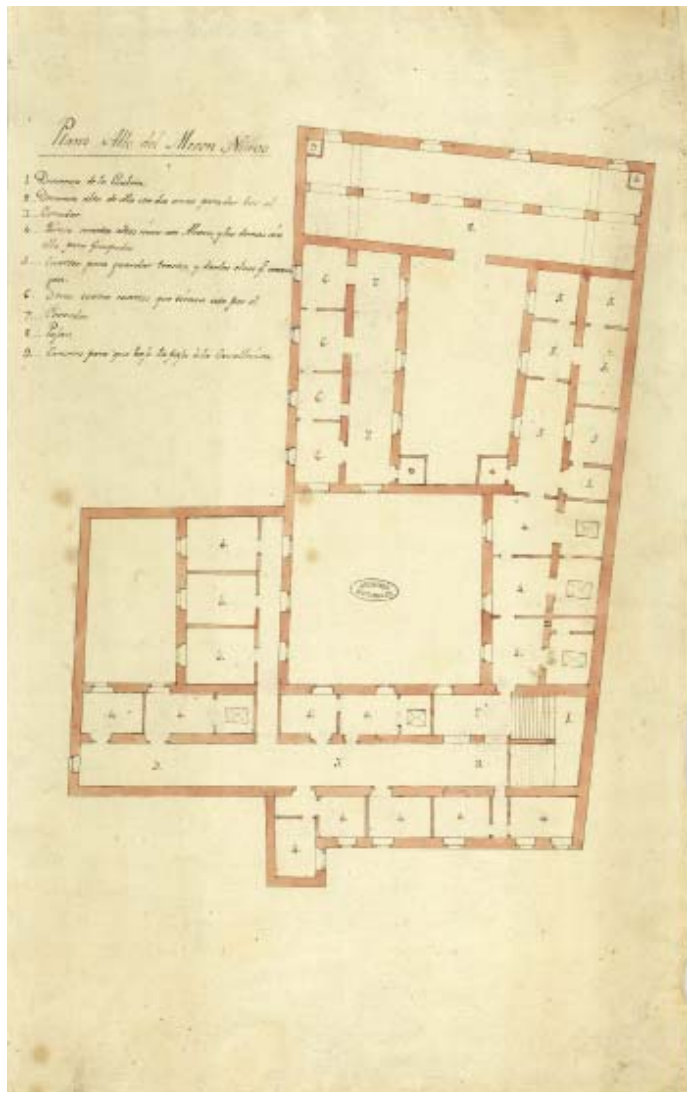

- Fig. 9. Plano alto del mesón nuevo. ANP, N/III/ Espagne/2/14.

Sin embargo, este innovador proyecto de mesón también fue abandonado como consecuencia de los problemas financieros

\footnotetext{
${ }^{75}$ T. M. FERNÁNDEZ DE MESA, Op. cit., pp. 78-79.
}

del VI conde. Y tras su muerte, sus sucesores en el título, centrados en las actividades cortesanas de Madrid, obviaron los planes de este, dejando en el olvido gran parte de sus iniciativas piadosas en la villa solariega del linaje $\mathrm{e}^{76}$.

\section{LA PUBLICITACIÓN DE LA CARI- TAS ILUSTRADA: LAS OBRAS PÍAS DEL VI CONDE DE FERNÁN NÚÑEZ EN EL ATLANTE ESPAÑOL}

Antes de finalizar cada uno de los proyectos que hemos comentado, el VI conde tenía ya prevista la estrategia de publicitación de su persona a través de los mismos. En efecto, al margen de diseñar estas fundaciones en el entorno del palacio, marcando la influencia del poder familiar sobre estas, dejó también estipulado que "tanto en las escuelas como en el hospital y casa de educacion, se pondrán sobre la puerta en piedra las armas iguales a las de la fachada del palacio y debajo escuela de niños ò niñas, casa de educacion de guerfanas de Sta. Escolástica, u Hospital de San Carlos fundado y dotado por el Conde D. Carlos año de 87"77 (Figs. 10 y 11).

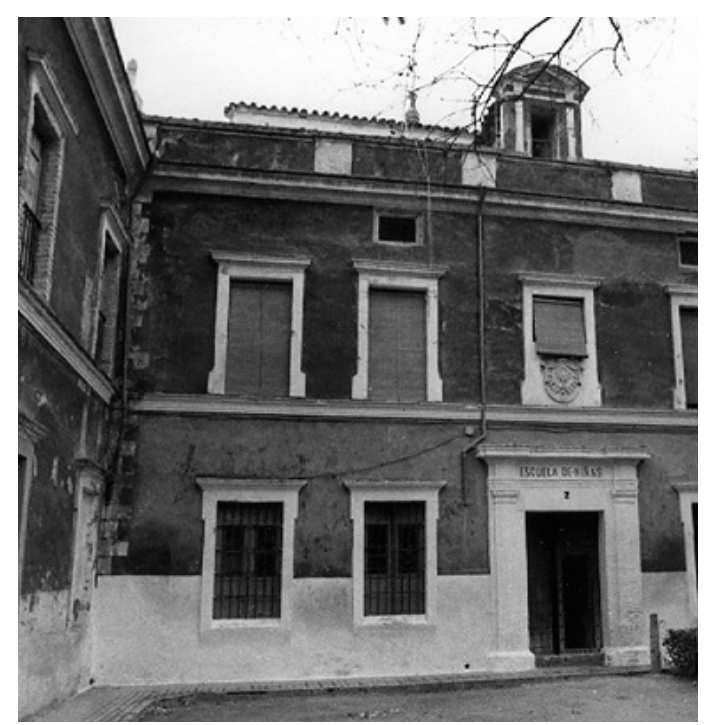

${ }^{76}$ La mayoría de las iniciativas del VI conde se desecharon y ya a comienzos del siglo XIX el estado de la administración de Fernán Núñez amenazaba ruina, véase: AHN-SN, Fernán Núñez, Caja 470, Documento 29-3.

${ }^{77}$ Ibídem, Documento 11-1. 


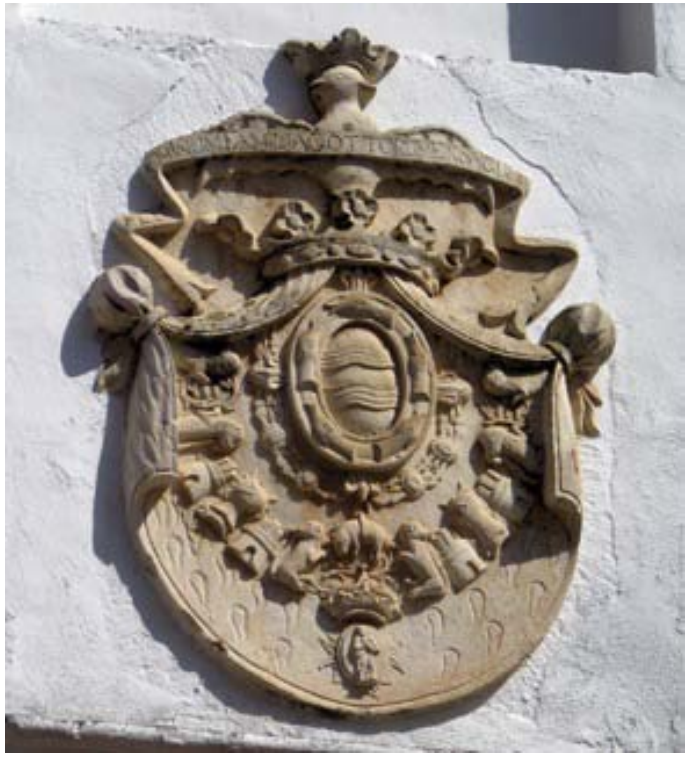

- Figs. 10 y 11. Fachada de la Escuela de Niñas Pobres y detalle del escudo de armas de los condes de Fernán Núñez. Foto del autor.

En esta misma línea, el VI conde pensó desde un primer instante en traspasar el ámbito local de su villa, publicitando así su piedad y carácter ilustrado entre un público más amplio. A esto se suma que, por esas fechas, tras su periplo diplomático en Lisboa, necesitaba promocionarse para aspirar a cargos de mayor importancia, en concreto deseaba recalar en las embajadas de Londres o París. De este modo, concibió las reformas ilustradas emprendidas en su villa como un instrumento válido para exhibir su imagen social. Por ello, con el objetivo de divulgar estos proyectos, promovió la publicación de una descripción de la villa de Fernán Núñez en El Atlante Español de Bernardo de Espinalt García, que resultaría un excelente escaparate para la exhibición de sus virtudes como prohombre ilustrado, donde la palabra y, fundamentalmente, la imagen se aunarían para ofrecer una visión de la villa modelada según su conveniencia personal y política $^{78}$. Resulta especialmente interesante su ahínco por distribuir dicha obra entre los aristócratas parisinos gracias a la intermediación del ministro francés de Asuntos Exteriores, el conde de Montmorin, ya que

\footnotetext{
${ }^{78}$ B. ESPINALT GARCÍA, Op. cit., pp. 5-63.
}

le permitió darse a conocer entre la nobleza francesa meses antes de asumir el cargo de embajador alli1 ${ }^{79}$. Tan efectiva debió ser la distribución internacional de este texto que Antonio Conca copió literalmente lo referido a las obras pías del VI conde de Fernán Núñez para su Descrizione odeporica della Spagna en $1795^{80}$.

La descripción de la villa fue escrita por el vicario de su administración, Juan García y Castro, aunque supervisada por el propio conde en dos ocasiones antes de ser enviada a Bernardo de Espinalt para su publicación. Como no podía ser de otra forma, gran parte de esta descripción estuvo dedicada a detallar las fundaciones de carácter piadoso que el VI conde tenía previsto crear ex profeso para su villa solariega, incidiendo en la viabilidad de las mismas. Así, lo referente a estas fundaciones pías se corresponde íntegramente con un escrito autógrafo del VI conde que incluyó entre las cláusulas de su testamento: Libro de oro y verdadero principio de la propia y ajena felicidad, donde detallaba minuciosamente el reglamento, la administración, el presupuesto y el plan de imposiciones progresivas con que formar los fondos de las citadas fundaciones, subrayando la veracidad de las mismas, aún por edificar ${ }^{81}$. En ese mismo sentido, hizo especial hincapié en destacar el respaldo económico que dichas fundaciones tendrían por parte de una institución de gran prestigio financiero como eran los Cinco Gremios Mayores de Madrid ${ }^{82}$, así como la gratificación de 120.000 reales de vellón concedida por Carlos III gracias al sal-

${ }^{79}$ Archives du Ministère des Affaires Etrangères, París (en adelante AAE), Correspondance politique, Espagne, vol. 624, fol. 196r-197r.

${ }^{80}$ A. CONCA, Descrizione odeporica della Spagna in cui spezialmente si da notizia delle cose spettanti alle belle arti degne dell'attenzione del curioso viaggiatore, Parma, 1795, t. III, pp. 194-201.

${ }^{81}$ C. J. GUTIÉRREZ DE LOS RÍOS, Vida de Carlos III, Madrid, 1988, vol. II, pp. 361-409.

${ }^{82}$ El 25 de junio de 1787, los miembros de los Cinco Gremios de Madrid aceptaron la propuesta del VI conde de Fernán Núñez para imponer 11.000 reales de vellón anuales al rédito del tres por ciento, véase: $\mathrm{AHN}$ SN, Fernán Núñez, Caja 470, Documento 7-5. 


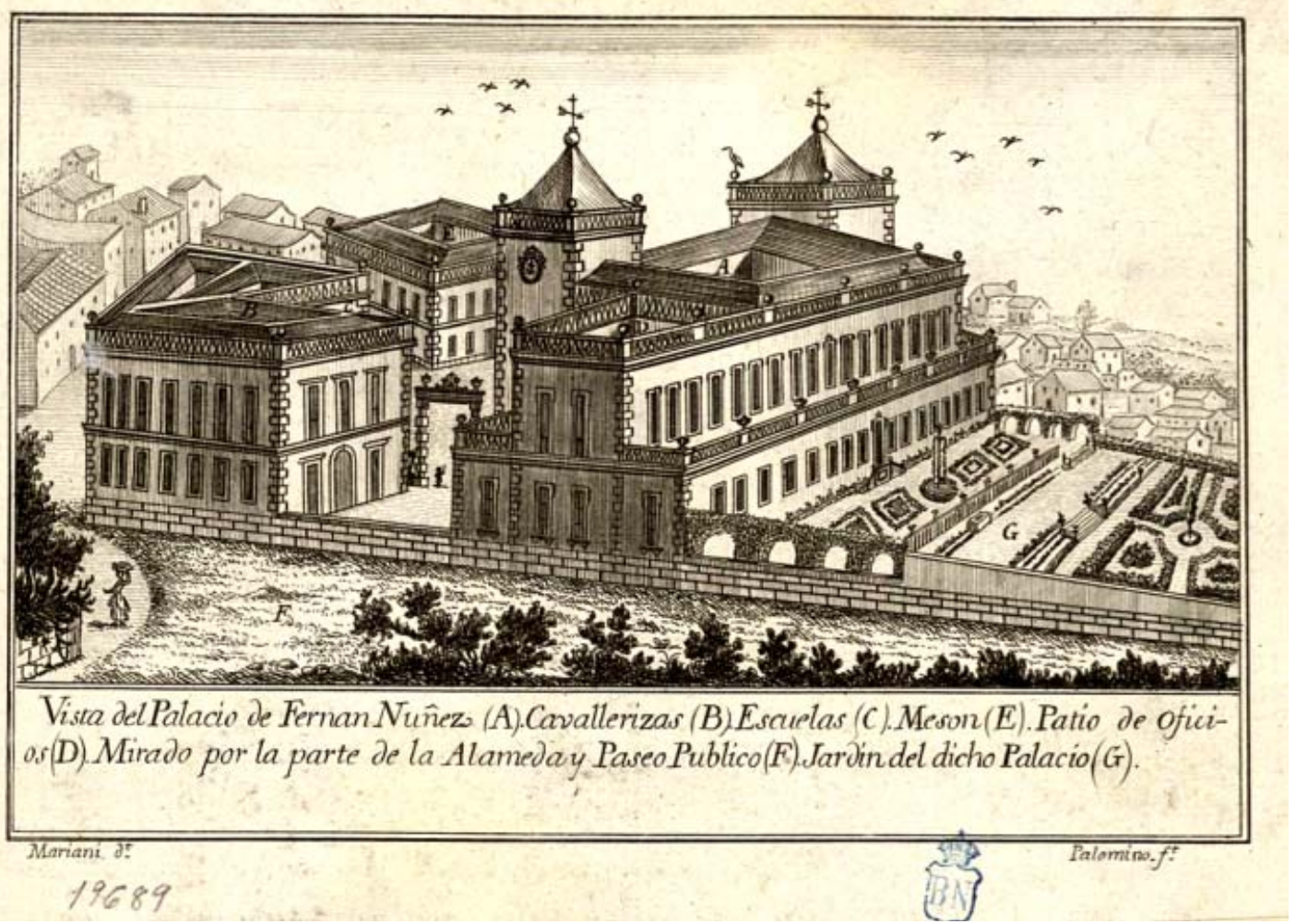

- Fig. 12. Juan Fernando Palomino. Vista de la plaza y entrada principal del palacio de Fernán Núñez. Aguafuerte y buril. BNE. ER/2108, Lám. 8.

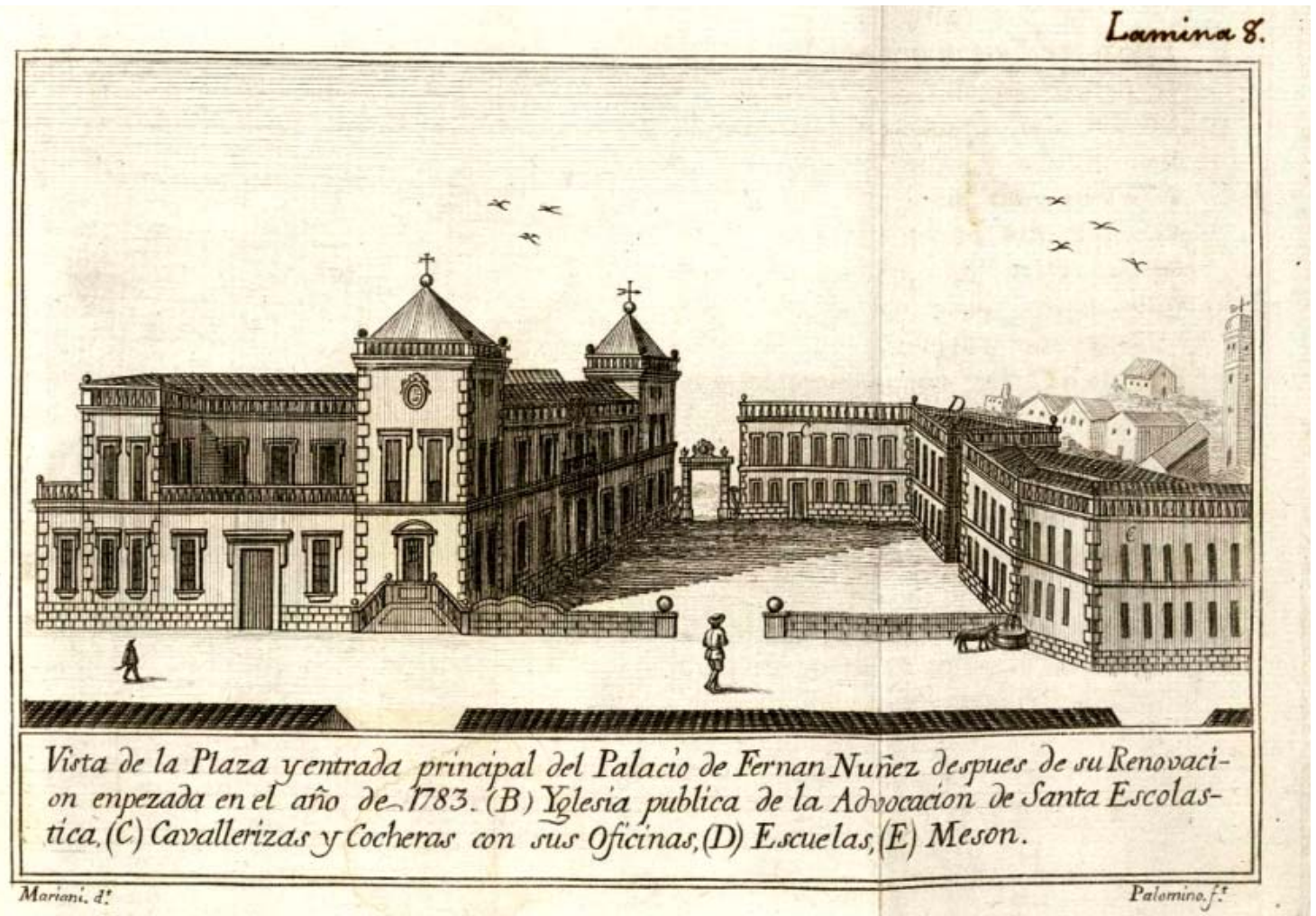

- Fig. 13. Juan Fernando Palomino. Vista del palacio de Fernán Núñez. Aguafuerte y buril. BNE. ER/2108, Lám. 9. 
vamento del navío San Pedro de Alcántara en las costas de Peniche, que serviría también para sufragar los gastos de estas obras pías ${ }^{83}$.

De igual modo, tan interesante como el contenido del texto fueron las imágenes que lo acompañaron, donde se representaban algunas de las obras pías proyectadas por el VI conde. Se trató de tres vistas de Fernán Núñez encargadas a su pintor de cámara, Vicente Mariani, que grabó una de ellas, $\mathrm{La}$ vista de la villa de Fernán Núñez desde encima del batán antiguo, mientras que las dos restantes alusivas al palacio familiar fueron grabadas en Madrid a finales de 1786 por el académico Juan Fernando Palomino a partir de los dibujos del citado Mariani. En lo referente a la representación de las obras pías del VI conde, tanto en la Vista de la Plaza y entrada principal del Palacio de Fernán Núñez después de su renovación empezada en el año de $1783^{84}$, como en la Vista del Palacio de Fernán Núñez ${ }^{85}$, los edificios de las escuelas públicas de niños y niñas pobres y el mesón de la plaza de armas aparecen representados perfectamente finalizados y unificados con el entorno del palacio familiar. Sin embargo, sabemos que aún estaban por concluir cuando se efectuaron dichos grabados. E incluso, se aludía a la casa de educa- ción de Santa Escolástica y al hospital de La Caridad que nunca llegarían a construirse. Por tanto, estas estampas respondieron a una imagen idealizada de la villa, diseñada a instancias del VI conde, pretendiendo presentar una visión modélica de sus iniciativas aún por terminar, sirviendo de esta forma a sus políticas de ostentación social (Figs. 12 y 13).

En definitiva, el VI conde de Fernán Núñez a través de El Atlante Español presentó un relato pormenorizado de sus obras e incluso anticipó proyectos futuros que nunca llegaron a materializarse. Así, sabemos que mientras las escuelas de niños y niñas pobres funcionaron correctamente durante muchos años, el resto de proyectos asistenciales, en la mayoría de los casos, no pasaron del acta fundacional aunque, eso sí, dejaron su rastro indeleble en el papel y en la opinión pública. Tanto es así que mediante $E l$ Atlante Español consiguió abrir nuevos canales para la sociabilidad con sus pares, en su gran mayoría ajenos al núcleo localista de su villa, permitiéndole construir una imagen de sí mismo como gran mecenas y benefactor, capaz de trasladar a una pequeña población periférica las innovaciones educativas y sanitarias de la Ilustración.

\footnotetext{
${ }^{83}$ B. ESPINALT GARCÍA, Op. cit., pp. 31-63.

${ }^{84}$ BNE, ER/2108, Lám. 8.

${ }^{85}$ Ibídem, Lám. 9.
} 